\title{
A Comparative Study of Critical Thinking Skills Between English and Japanese Majors in a Normal University
}

\author{
Fenglin Zhou ${ }^{1} \&$ Yuewu Lin ${ }^{1}$ \\ ${ }^{1}$ Foreign Languages College, Jiangxi Normal University, China \\ Correspondence: Yuewu Lin, Foreign Languages College, Jiangxi Normal University, Yaohu Campus, 99 \\ Ziyang road, Nanchang, Jiangxi, China.
}

Received: September 10, 2019 Accepted: November 10, 2019 Online Published: November 12, 2019

doi: $10.5539 /$ elt.v12n12p30

URL: https://doi.org/10.5539/elt.v12n12p30

\begin{abstract}
Critical thinking is one of the core objectives of talent training in higher education. Meanwhile, the cultivation of critical thinking skills in foreign language teaching has become more and more urgent, and it has also been written into the national standards for the training of foreign language talents. A good critical thinking includes both a skill dimension (Critical Thinking Skills) and a disposition dimension (Critical Thinking Dispositions). Critical Thinking Skills include interpretation, analysis, evaluation, inference, explanation and self-regulation. This study intends to explore the current situation of the critical thinking skills of undergraduates in foreign language majors (English and Japanese) in a Normal University, and then attempts to find out the similarities and differences in critical thinking skills between English majors and Japanese majors after years of study at college. The results show that a clear difference exists between English majors and Japanese majors in overall critical thinking skills. In particular, English majors are superior to Japanese majors. Another finding is that there are also differences between the two majors in the three core sub-skills of critical thinking skills, analysis, evaluation and inference.
\end{abstract}

Keywords: English majors, Japanese majors, critical thinking skills

\section{Introduction}

Critical thinking skills play an important part in the ability of critical thinking. It is quite necessary to promote the development of students' critical thinking skills. Critical thinking consists of two aspects: critical thinking dispositions and critical thinking skills. This study focuses more on critical thinking skills. As early as 1998, Professor Huang Yuanshen pointed out that the foreign language majors' absence of critical thinking exists generally, that is, foreign language teaching paid too much attention to the language structure itself and overemphasized the learning of language knowledge and language skills, such as listening, speaking, reading and writing, which is carried out merely by memorizing and comprehending. The higher cognitive skills, such as analyzing, evaluating, and creating, have not received sufficient attention, resulting in students' absence of critical thinking skills. However, recent studies (Wen, 2010; Zhang, 2018) on critical thinking between foreign language majors and other science or liberal arts majors reveal that foreign language majors are not weak in critical thinking and even superior to other majors.

Besides, foreign language majors may also show differences in critical thinking due to exposure to different foreign languages and cultures. This study involves two major foreign languages, English and Japanese, aiming at finding out the differences in critical thinking between English majors and Japanese majors.

\section{Research on Critical Thinking}

\subsection{Research on Critical Thinking Abroad}

Critical thinking refers to "reasonable reflective thinking focused on deciding what to believe or do" (Ennis, 1991), including critical thinking skills and critical thinking dispositions. But at that time, assessment criteria for critical thinking still lacked. The American Philosophical Association (APA) sponsored a two-year Delphi research project which included 46 persons active in critical thinking research, education, and assessment, and they conceptualized the critical thinking and constructed objectively scored standardized instruments, the California Critical Thinking Skills Test (CCTST) and the California Critical Thinking Disposition Inventory (CCTDI). The resulting consensus describes critical thinking as a kind of judgment, or more specifically, "a 
purposeful, self-regulatory judgment (Facione, 1990)". And a good critical thinking involves two dimensions, namely skills and dispositions. Analysis, evaluation and inference are the three core sub-skills of critical thinking skills. In addition, the Cambridge Assessment Group, the largest assessment company in Europe, has developed the Cambridge Thinking Skills Assessment (CTSA), which has been employed at Cambridge University since 2001. This study used the "the California Critical Thinking Skills Test" (CCTST Chinese Version) revised by Luo Qingxu in 2002.

With the development and application of these critical thinking measuring instruments, many foreign experts and scholars have carried out empirical researches on the development of critical thinking skills, which are conducted by cross-sectional or diachronic methods. Facione (1997) found that the critical thinking skills of American college students have steadily increased from the first grade to the fourth grade, with the most prominent advances occurring between the first and second grades. Hunter et al. (2014) used the Health Science Reasoning Test (HSRT) to make a horizontal comparison among three grades of undergraduates majoring in nursing in Australian colleges and universities, showing that except for analysis, critical thinking skills generally improved with the increase of grade. Compared with the cross-sectional method, the data collection process of diachronic study is more complex and more difficult, and the change of observation time may also affect the research results. For example, Cisneros (2009) used CCTST to conduct a one-year follow-up study on four grades of American pharmacy undergraduates, and found that the overall critical thinking skills of the students in each group did not change significantly. Miller (2003) used different versions of CCTST to continuously track the students majoring in pharmacy of North Dakota State University for 4 years. However, he found that the students' critical thinking skills increased year by year, with an overall increase of $14 \%$ at the end of the study.

Besides, many scholars have in-depth research on the influencing factors of the development of critical thinking skills, such as the educational environment, teaching methods and the cognitive concepts of language teachers in the cultivation of critical thinking skills. Abrami et al. (2008) found that there is a close relationship between the critical thinking skills teaching methods, teaching concepts and the development of students' critical thinking skills. Studies have shown that only if teachers have the initiative to develop students' critical thinking skills, can students' critical thinking skills get improved (Abrami et al., 2015). Mercado (2014) proposed that teachers' recognition of critical thinking skills is an important factor influencing the development of students' critical thinking skills. Regarding to the specific teaching method, PBL (Problem Based Learning), a student-centered and self-directed pedagogical approach, has been proved as a standard teaching method to enhance critical thinking. In a study developed in Iran, researchers reported that the PBL group achieved higher levels of critical thinking disposition when compared to the conventional teaching method group (Dehkordi and Heydarnejad, 2008). Similarly, a study on nursing students, whose critical thinking skills are similar in the pre-test, revealed that the PBL students experienced a significant increase $(\mathrm{p}=0.0004)$ in critical thinking skills (Moradi \& Taghadosi, 2016), unlike the conventional classes group.

\subsection{Research on Critical Thinking at Home}

Compared with foreign countries, the researches on critical thinking in China are relatively later and fewer. For foreign language teaching, the current empirical research on critical thinking skills is mainly concentrated on English majors.

Zhu's (2009) early research on the ability of critical thinking of undergraduates did not use specific test tools, but observed through argumentation writing by the subjects. The subjects were English and non-English majors from the first to fourth grades of three types of universities (comprehensive universities, science and engineering universities, financial and economic universities). The language used in the composition is English and Chinese. The study found that although the critical thinking ability of English majors showed in the argumentation was slightly weaker than that of other majors, it was generally on the rise.

Wen (2010) was the first scholar in China to conduct a large-scale survey on the ability of critical thinking of liberal arts college students, aiming at exploring the differences in the ability of critical thinking between English majors and other liberal arts majors. The subjects were the first, second and third year students from 14 liberal arts majors in 11 universities across the country. The research results showed that the English students' overall skills of critical thinking was higher than other liberal arts majors, but this gap gradually narrowed with the increase of grades.

Wen (2018) conducted a three-year follow-up study on the development trend of the ability of critical thinking of foreign language majors by following 139 English and German students in two different types of colleges. The study revealed that students' ability of critical thinking tended to grow during the three years and experienced the stage of "rise-flat-rise". However, the critical thinking ability of English and German students showed no 
significant differences at each stage.

Zhang (2018) did a comparative research on the critical thinking ability of 227 students from four foreign language majors (English, Russian, Japanese, and Korean) and two other majors (international politics and mathematics). The results indicated that there was a significant difference between foreign language majors and other majors in their critical thinking abilities, but the foreign language majors failed to show a marked progress in their critical thinking ability development throughout their four-year college life. And compared with the other two majors, the foreign language majors were superior to International Politics majors.

In conclusion, those studies mentioned above mainly focus on two issues: one is the development of critical thinking ability of English majors, and the other is the difference in critical thinking ability of English majors and other majors. The findings are inconsistent with each other. Zhu and Wen found that the foreign language majors' critical thinking ability showed a rising trend in their four-year study in college, while Zhang Jinsheng's research showed that this progress was not significant. Besides, compared with the other majors, Zhu Xiaotong pointed out that English students' critical thinking ability was slightly weaker than that of other majors, while Wen Qiufang and Zhang Jinsheng's research concluded that foreign language majors performed better than other majors in critical thinking ability. There are many reasons causing the differences in research findings, such as different research methods, different test instruments, different test participants, and so on.

This study examines the current state of the critical thinking skills of English and Japanese majors, and then makes a comparison in order to have a better understanding of the differences in critical thinking skills between the two foreign language majors, so that to further infer that whether there is a connection between critical thinking and different foreign languages. Through analyzing the differences and reasons, more effective measures can be taken to perfect the curriculum of foreign language majors, especially more interactions between different foreign languages, so that to largely enhance the critical thinking skills of foreign language majors.

\section{Theoretical Basis}

\subsection{The Relationship Between Language, Culture and Thinking}

The Sapir-Whorf hypothesis is an important theory about the relationship among language, culture and thinking. That is to say, the differences in structure, meaning and use of different languages in different cultures greatly affect the way of thinking of users. Different foreign languages learners are exposed to different languages and cultures, which may result in different levels of critical thinking skills. Therefore, this study intends to compare the critical thinking skills between English and Japanese majors so as to find out the similarities and differences in critical thinking skills between them after years of study of foreign languages at college.

\subsection{Two-dimensional Structure Model}

Until now, the most influential theoretical framework of critical thinking is the Two-dimensional Structure Model proposed by the "Delphi" project team. The model indicates that a good critical thinking includes both a skill dimension (Critical Thinking Skills, CTS) and a disposition dimension (Critical Thinking Disposition, CTD). CTS include interpretation, analysis, evaluation, inference, explanation and self-regulation. Interpretation is to categorize the problem, to define its characteristic, to decode and to clarify the meaning. Analysis is to distinguish the relationship among things. Evaluation is to make judgments on the credibility of statements. Inference is to reason and to make logical conclusions. Explanation is to state results, to justify procedures and to present arguments. Self-regulation is to reflect, to make self-assessment on one's cognitive activities and to correct the errors. The three core sub-skills of critical thinking are analysis, evaluation and inference which can be tested in CCTST developed by the "Delphi" project team. Besides, CTD contain truth-seeking, inquisitiveness, maturity, analyticity, open-mindedness, systematicity and self-confidence.

Table 1. Two-dimensional structure model (Facione, 1990)

\begin{tabular}{lll}
\hline & interpretation & $\begin{array}{l}\text { to categorize the problem, to define its characteristic, to decode and to clarify } \\
\text { the meaning }\end{array}$ \\
\cline { 2 - 3 } $\begin{array}{l}\text { Cognitive } \\
\text { Skills }\end{array}$ & analysis & to distinguish the relationship among things \\
& $\begin{array}{l}\text { evaluation } \\
\text { inference } \\
\text { explanation }\end{array}$ & $\begin{array}{l}\text { to make judgments on the credibility of statements } \\
\text { to reason and to make logical conclusions } \\
\text { to state results, to justify procedures and to present arguments }\end{array}$ \\
\hline
\end{tabular}




\section{$\begin{array}{ll}\text { to reflect, } & \\ \text { the errors. }\end{array}$}

$\begin{array}{ll}\text { Affective } & \text { 1) truth-seeking, 2) inquisitiveness, 3) maturity, 4) analyticity, 5) open-mindedness, 6) } \\ \text { Dispositions } & \text { systematicity and 7) self-confidence }\end{array}$

\section{Methodology}

\subsection{Research Questions}

This study seeks to answer two questions:

(1) What is the current situation of English and Japanese majors' critical thinking skills in a Normal University?

(2) Are there any significant differences in critical thinking skills between English and Japanese majors? If yes, to what degree?

\subsection{Participants}

The research was carried out at the Foreign Languages College in a Normal University. The subjects selected for this study are third-year undergraduate students majoring in English and Japanese. They have been studying in foreign languages for three years at university. The teaching content and teaching mode of foreign language have had a certain impact on students' thinking ability. Therefore, it is better to choose third-grade students as research subjects to explore whether there are differences in critical thinking skills between different foreign language majors. A total of 77 third-year undergraduate students were involved in the study, and 3 of them were excluded due to data missing. The valid number at last is 74, including 39 English majors and 35 Japanese majors.

\subsection{Research Instruments}

The framework of CCTST is based on the APA Delphi consensus conceptualization of critical thinking and developed by Facione (1994). It is a 34-item standardized multiple-choice test with five subscale scores including analysis, evaluation, inference, deduction, and induction. Each correct response is assigned one point. The test applied in this study is the "the California Critical Thinking Skills Test (CCTST Chinese Version)" revised by Luo Qingxu in 2002 which only consists of three subscale scores, analysis, evaluation and inference. And the deductive reasoning and inductive reasoning were integrated into the three subscales of the analysis (A) (0-9), evaluation (E) (0-14) and inference (Inf) (0-11) in the Chinese-version CCTST (2002), which produces an overall score (0-34) on critical thinking skills, Pearson $r=0.63, p<0.01, r / 2=(0.75-0.80), p<0.01$, and shows a good reliability, and good construct validity. Higher scores indicate stronger critical thinking skills. The specific classification of different levels in overall skills and the three sub-skills presents as follows.

Table 2. Classification standards for different levels in critical thinking skills

\begin{tabular}{llll}
\hline & Strong & Good & Weak \\
\hline Overall skills (0-34) & $\geq 25$ & $12-24$ & $0-11$ \\
Analysis (0-9) & $\geq 7$ & $4-6$ & $\leq 3$ \\
Evaluation (0-14) & $\geq 10$ & $5-9$ & $\leq 4$ \\
Inference $(0-11)$ & $\geq 8$ & $4-7$ & $\leq 3$ \\
\hline
\end{tabular}

\subsection{Data Collecting Procedures}

The test was conducted in May 2019. The third-year English and Japanese students who participated in the test are nearing the end of the junior year at university. Due to the different time schedule of different classes, the test time cannot be unified. The final test time was decided after negotiating with related teachers.

Every test had one person in charge. At the beginning of the test, the leader explained to the students that the test was just for academic research and would not be used for any other purpose.

\subsection{Data Analysis}

The data were analyzed using the SPSS17.0 for windows versions. Independent sample t-test analysis was employed to compare CCTST scores between English and Japanese majors. 


\section{Results and Data Analysis}

\subsection{The Overall Characteristics of Critical Thinking Skills of Foreign Language Majors (English and Japanese)}

There were 77 third-year undergraduate students participating in this study. The valid number at last is 74 , including 39 English majors and 35 Japanese majors.

\subsubsection{The Characteristics of Critical Thinking Skills of English Majors}

According to the scoring criteria of CCTST (Chinese Revised Edition), the overall results of English students' critical thinking skills are as follows.

Table 3 shows that there are 39 English majors participating in the test, including 3 people with an overall score of 25 points and above, accounting for $7.7 \%$ and these students are at a strong level of critical thinking skills. The overall score of 0 to 11 is also 3, indicating that the number of English majors who's critical thinking skills at a strong level is comparable to those at a weak level. More than $84.6 \%$ of English majors get an overall score of 12 to 24 points for critical thinking skills, which states that the critical thinking skills of English majors are generally at a good level.

Table 3. Distribution of different levels of CTS (English majors)

\begin{tabular}{lllll}
\hline Critical thinking skills & & Strong & Good & Weak \\
\hline Overall skills & score range & $\geq 25$ & $12-24$ & $0-11$ \\
& num. $(\%)$ & $3(7.7 \%)$ & $33(84.6 \%)$ & $3(7.7 \%)$ \\
Analysis & score range & $\geq 7$ & $4-6$ & $\leq 3$ \\
& num. $(\%)$ & $16(41 \%)$ & $18(46.2 \%)$ & $5(12.8 \%)$ \\
Evaluation & score range & $\geq 10$ & $5-9$ & $\leq 4$ \\
& num. $(\%)$ & $3(7.7 \%)$ & $27(69.2 \%)$ & $9(23.1 \%)$ \\
Inference & score range & $\geq 8$ & $4-7$ & $\leq 3$ \\
& num. $(\%)$ & $15(38.5 \%)$ & $17(43.6 \%)$ & $7(17.9 \%)$ \\
\hline
\end{tabular}

Note: overall score: 34 ; subscale scores: analysis-9, evaluation-14, inference-11.

As for the three subscales of critical thinking skills (analysis, evaluation and inference), most English majors are at a good level. Students at a good level of analysis, evaluation and inference are 18, 27, and 17, respectively, accounting for $46.2 \%, 69.2 \%$, and $43.6 \%$, respectively. It is worth mentioning that the number of English majors at a strong level of analysis is 16 , accounting for $41 \%$, followed by inference, 15 people, accounting for $38.5 \%$. On the other hand, there are only 3 people at a strong level of evaluation in English majors, accounting for only $7.7 \%$ of the total. It shows that English majors are good at analyzing, then inferring, while the evaluation skills are the weakest among the three sub-skills.

Table 4. Descriptive statistics of English majors' scores of CTS

\begin{tabular}{llllll}
\hline Critical thinking skills & Mean (Total scores) & Max. & Min. & SD & Level \\
\hline Overall skills & $18.79(34)$ & 30.00 & 10.00 & 4.61 & good \\
Analysis & $5.97(9)$ & 9.00 & 3.00 & 1.58 & good \\
Evaluation & $6.61(14)$ & 12.00 & 2.00 & 2.27 & good \\
Inference & $6.21(11)$ & 11.00 & 0.00 & 2.74 & good \\
\hline
\end{tabular}

Note: Overall skills: (1)strong level: $\geq 25$; (2)good level: 12-24; (3)weak level: 0-11.

Analysis:(1)strong level: $\geq 7$;(2)good level: 4-6;(3)weak level: $\leq 3$.

Evaluation:(1)strong level: $\geq 10$; (2)good level: 5-9;(3)weak level: $\leq 4$.

Inference:(1)strong level: $\geq 8$; (2)good level: 4-7; (3)weak level: $\leq 3$. 
Table 4 reveals the results of English majors' scores of CTS, including the means, the maximums and minimums, the standard deviations and the levels. The mean score of overall skills of English majors is 18.79, which is between 12 and 24, at a good level, with the highest score being 30 points and the lowest score being 10 points. And the mean scores of the three subscales, analysis, evaluation and inference, are 5.97, 6.61, and 6.21, respectively, which are all at a good level. The highest scores of analysis and inference are full marks, 9 and 10, respectively, and the highest score of evaluation is 12 points. However, the lowest score of inference is 0 , and the lowest score of analysis and evaluation is 3 and 2. From Table 4, it can be concluded that the critical thinking skills of English majors are generally at a good level. The three subscales, analysis, evaluation, and inference are also at a good level.

\subsubsection{The Characteristics of Critical Thinking Skills of Japanese Majors}

According to the scoring criteria of CCTST (Chinese Revised Edition), the overall results of Japanese students' critical thinking skills are as follows.

Table 5. Distribution of different levels of CTS (Japanese majors)

\begin{tabular}{lllll}
\hline Critical thinking skills & & Strong & Good & Weak \\
\hline Overall skills & score range & $\geq 25$ & $12-24$ & $0-11$ \\
& num. (\%) & $2(5.7 \%)$ & $29(82.9 \%)$ & $4(11.4 \%)$ \\
Analysis & score range & $\geq 7$ & $4-6$ & $\leq 3$ \\
& num. (\%) & $10(28.6 \%)$ & $22(62.8 \%)$ & $3(8.6 \%)$ \\
Evaluation & score range & $\geq 10$ & $5-9$ & $\leq 4$ \\
& num. (\%) & $0(0 \%)$ & $29(82.9 \%)$ & $6(17.1 \%)$ \\
Inference & score range & $\geq 8$ & $4-7$ & $\leq 3$ \\
& num. (\%) & $7(20 \%)$ & $16(45.7 \%)$ & $12(34.3 \%)$ \\
\hline
\end{tabular}

Note: overall score: 34 ; subscale scores: analysis-9, evaluation-14, inference-11.

Table 5 shows that there are 35 Japanese students participating in the test. Among them, 2 people have an overall score of 25 points and above, accounting for $5.7 \%$, and 12 to 24 points have reached 29 in number, accounting for $82.9 \%$. The overall score of 0 to 11 points is 4 , accounting for $11.4 \%$. It can be seen that the Japanese students' overall skills are at a good level, which is at the same level as English majors.

As for the three subscales of critical thinking skills (analysis, evaluation and inference), Japanese majors are mostly at a good level. Among them, there are 22 people at a good level of analysis, accounting for $62.8 \%$, and 29 for evaluation, accounting for $82.9 \%, 16$ for inference, accounting for $45.7 \%$. Students at a strong level of analysis, evaluation and inference are 10, 0 , and 7, respectively. No one gets scores more than 10 points in evaluation, which means no one is at a strong level of evaluation. But $82.9 \%$ of Japanese majors score 5 to 9 points, which indicates that most students are at a good level of evaluation. From the above detailed analysis, we can know that Japanese majors are better at analyzing, followed by evaluating, and inferring comes last, which is slightly different from that of English majors.

Table 6. Descriptive statistics of Japanese majors' scores of CTS

\begin{tabular}{llllll}
\hline Critical thinking skills & Mean (Total scores) & Max. & Min. & SD & Level \\
\hline Overall skills & $16.40(34)$ & 26.00 & 7.00 & 4.44 & good \\
Analysis & $5.34(9)$ & 8.00 & 1.00 & 1.63 & good \\
Evaluation & $6.31(14)$ & 9.00 & 3.00 & 1.95 & good \\
Inference & $4.74(11)$ & 10.00 & 0.00 & 2.54 & good \\
\hline
\end{tabular}

Note: Overall skills: (1)strong level: $\geq 25$; (2)good level: 12-24; (3)weak level: 0-11.

Analysis: (1)strong level: $\geq 7$; (2)good level: 4-6; (3)weak level: $\leq 3$.

Evaluation:(1)strong level: $\geq 10$; (2)good level: 5-9;(3)weak level: $\leq 4$. 
Inference:(1)strong level: $\geq 8$;(2)good level: 4-7;(3)weak level: $\leq 3$.

As Table 6 shows, the mean score of overall skills of Japanese majors is 16.40 , between 12 and 24, which is at a good level, with a maximum score of 26 and a minimum score of 7 . With regard to the three subscales, analysis, evaluation and inference, the mean scores are 5.34, 6.31 and 4.74, respectively, which stay between 4-6, 5-9, 4-7, respectively, all at a good level. The highest score for analysis is 8 , and 9 for evaluation, 10 for inference. As for the lowest score, 0 for inference, 1 for analysis and 3 for evaluation. From Table 6, we can find out that the critical thinking skills of Japanese majors are generally at a good level, so are the three subscales, analysis, evaluation, and inference.

\subsection{Comparison of CTS Between English and Japanese Majors}

There are 74 undergraduate students participating in this test, including 39 English majors and 35 Japanese majors. From Table 7, we can clearly see the differences between English majors and Japanese majors in critical thinking skills and the three subscales, analysis, evaluation and inference. For the mean scores of overall skills and the three subscales, English majors are higher than Japanese majors. The independent sample T-test results show that there is a significant difference in critical thinking overall skills between English majors and Japanese majors $(\mathrm{P}=.026<0.05)$, indicating that the critical thinking skills of English majors are stronger than Japanese majors. Regarding to the three subscales, it shows no significant difference in analysis and evaluation between English majors and Japanese majors $(\mathrm{P}=.095, .545>0.05)$, which means that they share the same level of analysis and evaluation. However, we surprisingly found that there is a significant difference in the subscale of inference between English and Japanese students $(\mathrm{P}=.020<0.05)$, that is, English majors perform better in inferring than Japanese majors.

Table 7. Independent sample T-test

\begin{tabular}{lllllll}
\hline Variables & $\begin{array}{l}\text { English } \\
\mathrm{M}\end{array}$ & $\begin{array}{l}\text { Major } \\
\mathrm{SD}\end{array}$ & $\begin{array}{l}\text { Japanese } \\
\mathrm{M}\end{array}$ & $\begin{array}{l}\text { Major } \\
\mathrm{SD}\end{array}$ & $\mathrm{t}$ & Sig (2-tailed) \\
\hline $\mathrm{N}$ & 39 & & 35 & & & \\
Overall skills & 18.79 & 4.61 & 16.40 & 4.44 & 2.271 & .026 \\
Analysis & 5.97 & 1.58 & 5.34 & 1.63 & 1.693 & .095 \\
Evaluation & 6.61 & 2.27 & 6.31 & 1.95 & .609 & .545 \\
Inference & 6.21 & 2.74 & 4.74 & 2.54 & 2.376 & .020 \\
\hline
\end{tabular}

Note: Overall skills: total score-34 4 (1)strong level: $\geq 25$; (2)good level:12-24; (3)weak level: 0-11.

Analysis: total score-9 (1)strong level: $\geq 7$;(2)good level: 4-6; (3)weak level: $\leq 3$.

Evaluation: total score-14 (1)strong level: $\geq 10$; (2)good level: 5-9; (3)weak level: $\leq 4$.

Inference: total score-11 (1)strong level: $\geq 8$; (2)good level: 4-7;(3)weak level: $\leq 3$.

\section{Conclusions and Discussions}

According to the detailed analysis above, we can draw the following three conclusions:

(1) The critical thinking skills of English majors are generally at a good level, so are the three subscales, analysis, evaluation and inference. But through comparing, we found that English majors are slightly better at analyzing; then followed by inferring, and evaluating comes last.

(2) The critical thinking skills of Japanese majors are also at a good level, so are the three subscales, analysis, evaluation and inference. But what is different from English majors is that Japanese majors perform better in analysis, evaluation next, and inference last.

(3) A comparative study in critical thinking skills of English majors and Japanese majors found that English majors perform better in critical thinking than Japanese majors. For the three subscales, there is no significant difference in analysis and evaluation, but in inference, English majors are significantly stronger than Japanese majors.

Then, we'll have a discussion about these findings. 
(1) The reason why English students' critical thinking skills are stronger than Japanese students may be as follows.

Firstly, English majors have learned English for nearly 10 years starting early at primary school before they came to university. They have a better language foundation, rich experience in language learning, deeper understanding of English and its culture, which is beneficial for their further development of critical thinking skills. However, Japanese majors are mostly beginners when they come to the university. What they learn in the first and second year at university is just equivalent to the level of the fourth and fifth grades of elementary school in Japan. It takes most of their time to learn those basic lessons. Besides, most students learn Japanese merely by imitating and memorizing at early stage and hardly involving those high levels of cognitive competence such as application or creation, which to some extent, inhibits the development of Japanese majors' critical thinking skills. Secondly, compared with other foreign language majors, English is more versatile, and it can attract more outstanding students who have better critical thinking skills, so after four years' study at university, their critical thinking skills may be stronger than others. Thirdly, the different levels of critical thinking skills between English majors and Japanese majors may result from the influence brought by English culture and Japanese culture.

(2) For the three subscales of critical thinking skills, both English and Japanese majors show a stronger level in analysis. The skill of analyzing emphasizes the decoding, clarification and understanding of meaning, which is a frequently trained and necessary skill for college students who have passed the college entrance examination. As a result, compared with evaluation and inference, English and Japanese majors are better at analyzing.

(3) In terms of evaluation and inference, English and Japanese majors show different preference. English majors are better at inferring, while Japanese majors show a higher level of evaluation. After checking the English and Japanese training program of the Normal University, we found that in the Japanese training program, it declares "to enable Japanese majors to have a good command of the basic theory and method of literary criticism", indicating that in language teaching, teachers would consciously improve students' ability of appreciation and criticism of literary works, and that is what the evaluation skill emphasizes. However, this has not been explained in the training program for English majors. As for inference, westerners pay more attention to logical thinking than easterners, so that English majors, exposed to western culture for a long time, show higher level of inference skill than Japanese majors.

The performance in critical thinking skills of foreign language majors also has some implications for teaching:

(1) Creating teaching methods. In addition to imparting professional knowledge, teachers should pay more attention to cultivating students' habits of critical thinking. By asking students to read extensively after class and then discussing and expressing their own opinions in class, by more emphasizing the explanation and analysis of thinking process, by focusing more on guiding students how to learn, how to analyze and understand, rather than simply telling students what it is, their critical thinking skills can get largely developed.

(2) Optimizing the curriculum. Generally speaking, the curriculum in our country still has some shortcomings such as lacks of variety and interdiscipline, too much focus on skill training, less humanistic quality training, and relatively lagging teaching content. Under such a curriculum, it is undoubtedly difficult to improve the critical thinking skills of foreign language students. Therefore, it is very urgent to optimize the existing curriculum to effectively facilitate the development of their critical thinking skills, making foreign language majors not only instrumental, but also humanistic.

\section{Summary}

The results of the research shows that the critical thinking skills of foreign language majors are generally at a good level, but there is still much room for improvement. The necessity and urgency to improve foreign language majors' critical thinking skills becomes a common sense, but how to effectively achieve that still needs further research.

There are still some deficiencies in this study. The first is that the number of samples involved is too small. Secondly, due to the limited conditions, the comparative study of critical thinking skills is only conducted in two foreign language majors, English and Japanese. If more foreign language majors such as French and German are involved, it will better reflect the level of critical thinking skills of foreign language majors, and can even compare with other liberal arts majors or science majors to explore the differences in critical thinking skills, so that to give more effective suggestions for the cultivation of foreign language talents.

\section{References}

Abrami, P. C. (2008). Instructional interventions affecting critical thinking skills and dispositions: A stage 1 
meta-analysis. Review of Educational Research, 78(4), 1102-1134. https://doi.org/10.3102/003465430 8326084

Abrami, P. C. (2015). Strategies for teaching students to think critically: A meta-analysis. Review of Educational Research, 85(2), 275-314. https://doi.org/10.3102/0034654314551063

Cisneros, R. M. (2009). Assessment of critical thinking in pharmacy students. American Journal of Pharmaceutical Education, 73(4), 1-7. https://doi.org/10.5688/aj730466

Dehkordi, A. H., \& Heydarnejad, M. S. (2008). The impact of problem-based learning and lecturing on the behavior and attitudes of Iranian nursing students. A randomised controlled trial. Dan. Med. Bull, 55, 224-226.

Ennis, R. (1991). Critical thinking: A streamlined conception. Teaching Philosophy, 14, 15-24. https://doi.org/10.5840/teachphil19911412

Facione, N. C., \& Facione, P. A. (1997). Critical Thinking Assessment in Nursing Education Programs: An Aggregate Data Analysis. Millbrae, California, IL: California Academic Press.

Facione, P. A. (1990). Critical Thinking: A statement of expert consensus for purposes of educational assessment and instruction. Millbrae, California, IL: California Academic Press.

Facione, P. A., \& Facione, N. C. (1994). The California critical thinking skills test: Test manual. Millbrae, California, IL: California Academic Press.

Hunter, S. (2014). Critical thinking skills of undergraduate nursing students: Description and demographic predictors. Nurse Education Today, 34(5), 809-814. https://doi.org/10.1016/j.nedt.2013.08.005

Huang, Y. S. (1998). The absence of critical thinking. Foreign Languages and Their Teaching, 7, 2+18.

Luo, Q. X, \& Yang, X. H. (2002). The revision of the California Critical Thinking Skills Test (CCTST). Journal of Psychological Science, 6, 740-741.

Mercado, S. B. (2014). Teaching Critical Thinking in Secondary Foreign Language Classrooms. Los Angeles, CA: University of Southern California.

Moradi, T., Taghadosi, M. (2016). The effect of problem-based learning clinical education on nursing student's critical thinking. Future Med. Educ. J., 6, 20-25.

Wen, Q. F. (2010a). A comparative study of critical thinking between English majors and other liberal arts college students in China. Foreign Language Teaching and Research, 5, 350-355.

Wen, Q. F., \& Sun, M. (2018). Research on the development of critical thinking in foreign language majors. Foreign Language World, 6, 12-19.

Zhang, J. S. (2018). A comparative study of critical thinking skills in foreign language students. Journal of Xi'an International Studies University, 26(2), 72-76.

Zhu, X. S. (2009). Research on the characteristics of English majors' critical thinking by argumentation writing. Beijing: Guangming Daily Press.

\section{Copyrights}

Copyright for this article is retained by the author(s), with first publication rights granted to the journal.

This is an open-access article distributed under the terms and conditions of the Creative Commons Attribution license (http://creativecommons.org/licenses/by/4.0/). 